\title{
Deployment of Knowledge Management in a PLM Environment: A Software Integrator Case Study
}

\author{
Sébastien Nila ${ }^{1}$, Frédéric Segonds ${ }^{1}$, Nicolas Maranzana ${ }^{1}$, \\ and Dorothée Crepe ${ }^{2}$ \\ ${ }^{1}$ Arts et MetiersParisTech, LCPI, \\ 151 bd de l'Hôpital, 75013 Paris, France \\ Sebastien.nila@gmail.com, \{frederic.segonds, \\ nicolas.maranzana\} @ensam. eu \\ ${ }^{2}$ Keonys 308 Bureaux de la Colline, 92210Saint-Cloud, France \\ Dorothee.crepe@keonys.com
}

\begin{abstract}
The past years have seen growing investments in the area of PLM by several industries. In today's industrial production, PLM is an essential tool to cope with the challenges of more demanding global competition and evershortening product lifecycles. Complex products require collaboration of large specialist networks. Knowledge Management (KM) can be apprehended in two manners: the defensive manner builds the stock of knowledge to face the departures of personnel, or, the offensive manner sees in the knowledge development an advisability to generate new products. The link between PLM and $\mathrm{KM}$ is interesting as it can help answering "on field" problems. In this paper we first make a state of the art of knowledge and KM in a PLM context. Then we propose a methodology to deploy $\mathrm{KM}$ in the particular case of a software integrator. Finally, we propose an experimental protocol that will allow us to improve a tool demonstrator in an agile way.
\end{abstract}

Keywords: PLM, Knowledge Management, methodology, software integrator.

\section{Introduction}

PLM systems are nowadays widely used in engineering design. The economic context forces industries to achieve more and more ambitious projects with ever shortening time and money. On the other side, knowledge is the most important thing in a company, and is mainly stored in the employees' mind, as illustrated in Figure 1, extracted from (Segonds 2011).It seems worth remembering that most of the knowledge can't be stored on a computer, because it is the fruit of Human. Design choices made are often implicit and very few are archived in any software. This kind of knowledge is, at the moment, difficult to store and manage. The progressive integration of KM in PLM systems is means to improve knowledge spread.

In this paper, we first make a state of the art of knowledge and KM in a PLM context. Then we propose a methodology to deploy KM in the particular case of a 


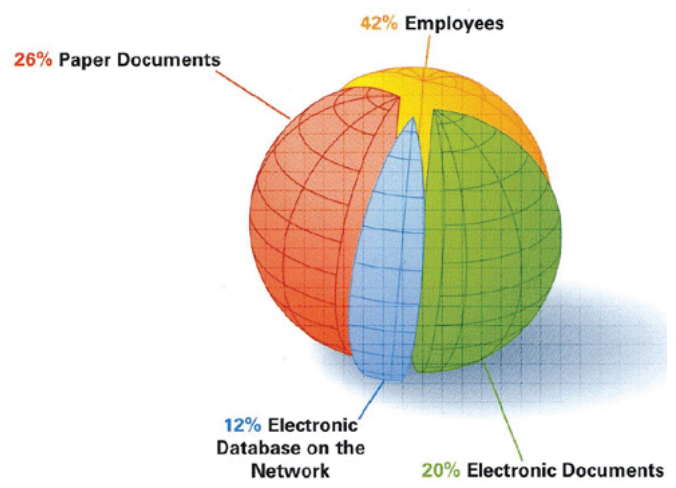

Fig. 1. distribution of knowledgeinproduct design, extracted from (Segonds, 2011)

software integrator. Finally, we propose an experimental protocol that will allow us to improve a tool demonstrator in an agile way.

\section{$2 \quad$ PLM Context and Associated Challenges}

\subsection{Evolution of Design Methodologies and Dedicated Software Tools}

In a context marked by increasing competition, businesses must suit their organization to the demands of their customers. In this context, the reduced duration of development cycles and the increasing complexity of mechanical systems force businesses to involve actors from various professional and cultural backgrounds in collaborative projects. The organization of design teams has also had to adapt to these changes in the industrial context.

Figure 2 illustrates the changing patterns in the formation of new product development teams as these moved to greater collaboration and virtuality.

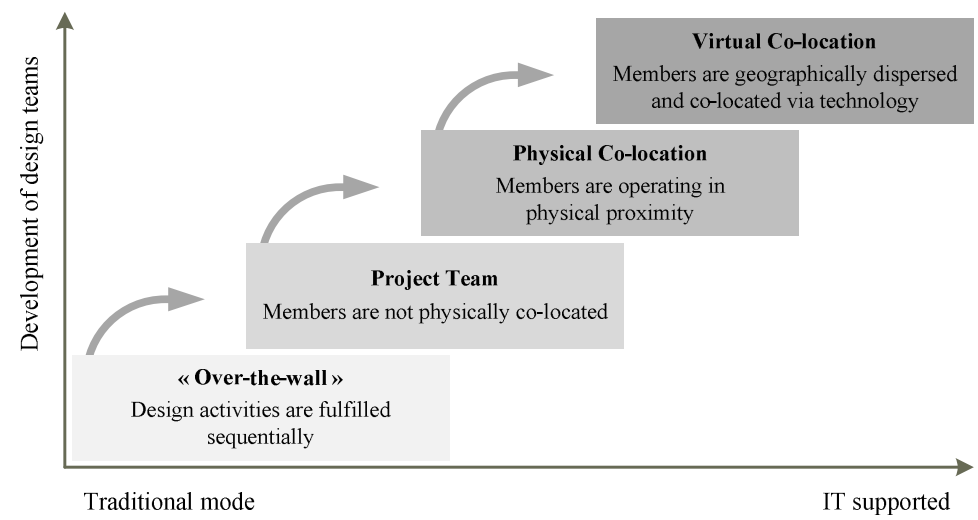

Fig. 2. Changes in design teams adapted from (Sharifi et al., 2001) 
Obviously, these industrial evolutions have been supported by evolutions in work methods and in the associated digital tools, such as PLM solutions. At the same time, research is actively being carried out to develop methodologies and technologies to support geographically dispersed teamsin order to facilitate product development processes (Dodgson et al.,2006). The objective is to organize collaborative work based on the rapid evolution of information technologies. Research works and commercial systems have appeared to provide solutions for collaborative and distributed product development, and the practical applications are getting more and more mature (Li et al., 2006).

In an attempt to improve productsand reduce costs and time to market, concurrent engineering (Solhenius, 1992) or lifecycle engineering has emerged as an effective approach to address these issues in a competitive global market (Asiedu et al.,1998).Influenced by the NTIC development, global economic challenges, and decentralized structures, the objectives and scope of Product Data Management technology (PDM) have changed. Thus, in the early 2000s, PLM emerged as a solution to adapt industrial design to the demands of globalization. Indeed, as PLM addresses the entire lifecycle of the product, it has a cross-functional nature and deals closely with the way a company runs (Garetti et al., 2005). Collaborative design has been the subject of numerous studies. With the development of PDM, PLM and associated workflows, software firms have proposed solutions to the everyday problems of engineering design departments (versioning of documents, naming etc.). The PLM approach can be viewed as a trend toward a full integration of all software tools taking part in design and operational activities during a product life cycle (Garetti et al., 2005; Donati et al. 2010). Therefore, PLM software packages need product data management system; synchronous and asynchronous, local and remote collaboration tools; and if necessary, a digital infrastructure allowing exchanges between software programs. These systems are distributed technological information systems for archiving, administrating and providing all product or facility related information in required quality and at the right time and place (Ameriet al., 2005): they are nowadays real key points for companies businesses.

\subsection{PLM Systems: Key Points for Business}

A product is a complex "fabricated-assembled" element, comprising a large number of components, functions and process steps (Clark et al., 1991). To be or stay competitive, anindustry needs to be different than others (Danneels, 2002), that's why most of industries are in a transformation step to be more responsiveness about customers and competitors. PLM is, for a long time, considered as a key for business and the transformation of engineering processes (Rekieket al., 2002). Moreover, PLM solutions are efficient tools to store knowledge and facilitate their re-use. In the next section, we will discuss about the integration in PLM systems of expertises generated all along projects, also known as knowledge. 


\section{Knowledge Management and PLM}

\subsection{Knowledge Management}

According to Wiig (1997), knowledge is information combined with experience, context, interpretation and thinking. It is a high value form of information that is ready to apply to decisions and actions. Simply put, knowledge can be defined as the integration of ideas, experience, skills that have the potential to create value for a business by informing decisions and improving performance. In this view, knowledge is a key enabler to organizational success. However, in order to be useful, knowledgemust be available, accurate, effective and accessible.

In NewProduct Development (NPD), there is an implicit distributed interaction among different actors.As we enter the knowledge society, ownership of knowledge and information as a source of competitive advantage is becoming increasingly important. In other words, organizations depend more on the development, use and distribution of knowledge based competencies. Consequently, organizations are focus more attention to the concept of managing their knowledge base in order to increase competitive advantage, through effective decision making and innovation (Nonaka et al., 1995; Davenport et al., 1996; Sveiby et al., 1997).

Knowledge is a key resource that must be managed if improvement efforts are to succeed and businesses are to remain competitive in a networked environment (Gunasekaran, 1999). Indeed, it is a big adds value for organizations to capitalize on knowledge sources by trying to predict how the new product will perform in an unknown context. From the social perspective, the challenge consists in sharing knowledge and interconnecting people that are imagining these future conditions.

Managing knowledge is about creating an environment in continuous creation, aggregation, use and reuse of both organizational and personalknowledge in the pursuit of new business value. KM can be considered as a systematic and organized attempt to use knowledge within a company to transform its ability to generate, store and use knowledge in order to improve performance. In short, the leading purpose of $\mathrm{KM}$ is to make knowledge accessible and reusable to the organization.

As PLM, KMhas a true add value. As we will discuss in next chapter (4), these two methods (and dedicated tools)can be combined in order to deliver knowledge all along the lifecyle of a product.

\subsection{PLM and KM Integration}

Currently, there is alack of studies on information flows needed acrossproduct lifecycle operations. Thus, the unavailability of explicit flows leads to a certain degree of inefficiency in performing lifecycle operations. Methods dedicated to efficiently represent, control and search information flows are critical. KM requires the identification of information flows and their efficient management, which can play an important role in analyzing and taking decisions during the product lifecycle (Jun et al., 2012).As Ouertani et al. (2011) mentioned, querying and sharing product knowledge is becoming a key issue in enterprise. Hence, the success of PLM and KM 
integration lies in identifying what kind of information are available in the other phase, and how we can use them in order to streamline business processes.

An emergent challenge consists in providing a context-driven access to federated information and knowledge, fostering cross-discipline collaborations between actors to improve quality in product development. In the next section, we will try to address this challenge by proposing a methodology to deploy KM in PLM environment.

\section{Proposition of a Methodologyto Deploy KMin PLM Environment}

\subsection{Industrial Context: The Keonys Company}

The context and problem of identifying and thereafter representing, analyzing and managing information and knowledge in an organization has always been very crucial to achieve business goals in an efficient and flexible way. Particularly in a PLM context, the issue of information overload is growing in importance. Among the existing integrators, Keonys the European leader in the integration of PLM solutions is in constant development, both in its workforce as its revenue and services offered to customers. In the same way the company's knowledge, defined as expertise and know-how, is in growth and is divided in different branches of the group in Europe.In this growing environment, Keonys is looking for a way to capitalize on the knowledge of the company and arrange them in different ways in order to define Best Practices.

The purpose of this paper is to propose a methodology which can answer the needs of development of Keonysthrough the integration of KM in PLM environment. It includes several points, from the categorization of company knowledge to the identification of an adapted Knowledge Based Engineering System (Sriram, 2006).In the next section, we describe the proposed methodology.

\subsection{Proposed Methodology to Deploy KM in PLM Context}

Agile methodology is an alternative to traditional project management, typically used in software development. It helps teams respond to unpredictability through incremental, iterative work cadences, known as sprints. Agile methodologies are an alternative to waterfall, or traditional sequential development.

Agile development methodology provides opportunities to assess the direction of a project throughout the development lifecycle. This is achieved through regular cadences of work, known as sprints or iterations, at the end of which teams must present a potentially shippable product increment. By focusing on the repetition of abbreviated work cycles as well as the functional product they yield, agile methodology is described as "iterative" and "incremental." In waterfall, development teams only have one chance to get each aspect of a project right. In an agile paradigm, every aspect of development, requirements, design, is continually revisited throughout the lifecycle. 
The main advantage is its flexibility during the development. This method is oriented on code development and ensures an adapted implementation of the functionalities. It tends to improve how software and process are developed. Segonds (2011) developed a generic model based on a collaborative environment by integrating an agile development method. We base on this model to develop a methodology attempting to integrate KM approach seen in the state of art (Figure 3).

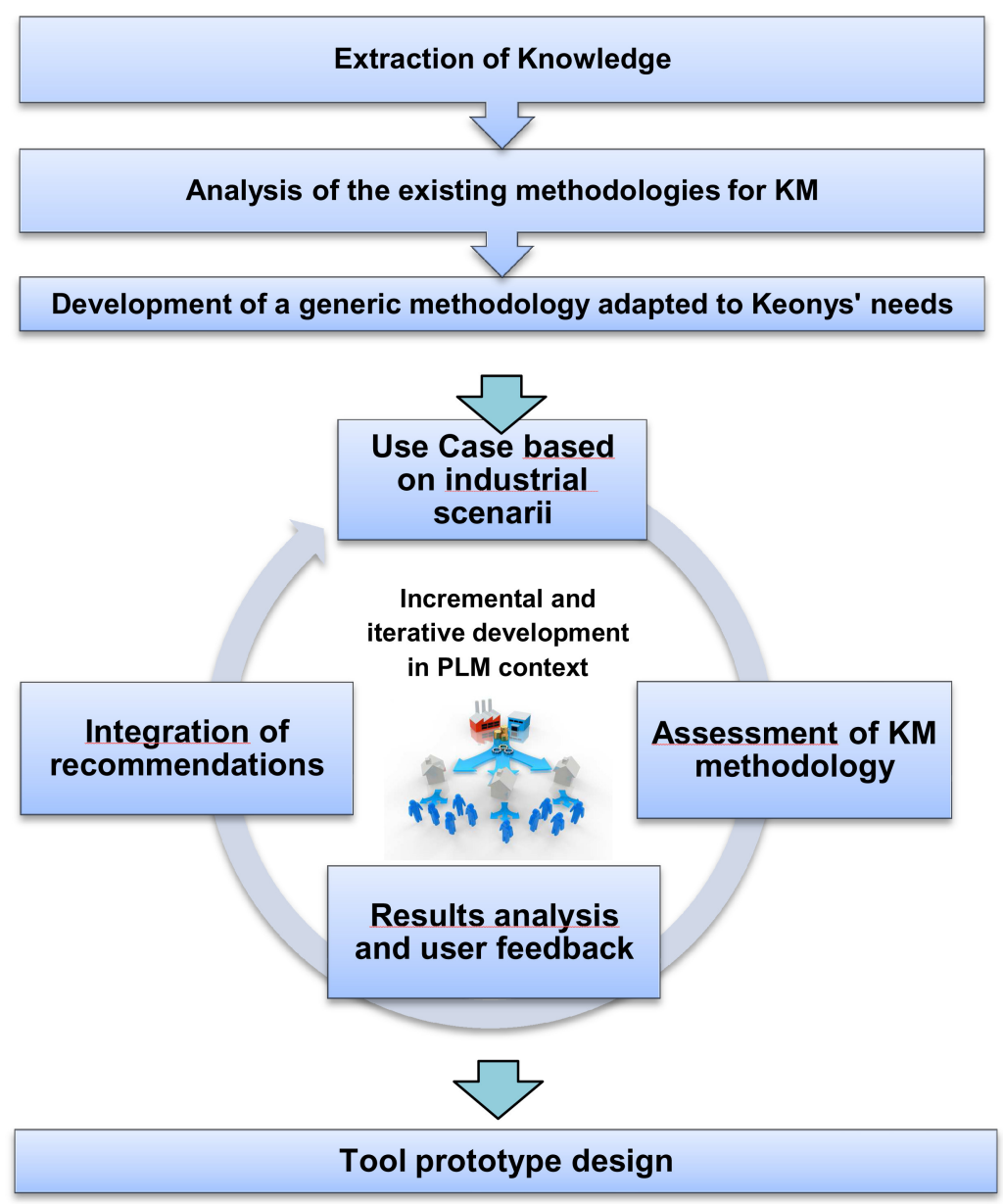

Fig. 3. PLM interface model design with KM integration and agile development, adapted from Segonds (2011)

Considering the case of Keonys, this company is oriented in a standardization development strategy, they want to create generic application in PLM tools to make an add value and to be different from their competitors. The group is separated in different work places. This method is a good way to develop a prototype tool adapted 
to the way of work of this company. With the consulting activity, it's difficult to group all developers in the same moment to adapt a methodology. The incremental and iterative development help to develop the methodology in asynchronous time.

\subsection{Experimental Knowledge Extraction and Methodology Test}

The first phase of the proposed methodology is one of the most important as it allows the identification of knowledge in the company. To identify knowledge, user interviews are planned with different experts. The user interview is a method used to collect oral data from individuals or groups in order to derive information from specific facts or representations. The relevance, validity, and reliability of this information are assessed based on the goals of this data collection. The main types of interviews include the directed interview, the semi-directed interview, and the free interview (Blomberg et al., 1993). Considering our goals, the type of interview that seems to suit our needs best is the semi-directed interview. It allows us to collect precise data in a reasonable length of time and fosters a genuine dialogue between the interviewer and interviewee. The second phase is the analysis of the existing methodologies of KM to inventory functionalities. Then, in order to test the reliability and validate the proposed methodology, user tests will be run with experts and novices. According to Nielsen and Laudauer (1993), no more than ten participants are needed for a usability tests. The recommendations made during the tests will help us to develop a tool prototype in an incremental and iterative way to fulfill the requirements expressed by the users.

\subsection{Results}

At this moment of study, the three first phases of the Agile methodology has been treated.

\subsubsection{Knowledge Extraction}

For the extraction knowledge phase, a first approach was to target people who are in charge of developing activities. After an overview of the company we selected ten employees in three different entities, a questionnaire was created for a first approach. The questionnaire goals is to refer project, industry, type of development, time spent. The result of this questionnaire show a first difficulty to manage people to answer correctly and in time, it comes from the volatility of concerned people and from their manager to push them. The data collected with the questionnaire is well organised and structured. Every project referenced is followed by the development code, use instruction and setup instruction. This first approach is a good way to get direct or phone contact and speak more easily to developer if there is missing explanation or missing data in the questionnaire. After this step all developmentwas tested and analysed to add new information's like usability, adaptability, pertinence. All information collected by questionnaire, interviews, test and analysis helped to categorize data and put priorities. 
The second phase of the methodology is to analyse existing KM methodology in the company. There is four main tools using KM (Opportunity Review Business, Enterprise Resource Planning, Service Request, Intranet). These tools serves the company to capitalize data and information in an end to end way, from the opportunity to the billing. After a deep analyse of these tools, there is not the possibility to use one of them or a part of one of them to answer to Keonys needs concerning the development activity.

\section{Conclusion}

This article proposes to integrate KM approach to improve PLM systems. The state of art demonstrates that evolutions in design methodologies and dedicated software tools have promoted PLM and KM as key points for companies businesses. The presented methodology combines agile software development in PLM context. KM will allow us to provide a tool prototype dedicated to Keonys company. The extension of this method to others companies could increase user's satisfaction and, as a consequence, the efficiency of the company through the use of KM integrated in PLM environments.

\section{References}

1. Ameri, F., Dutta, D.: Product Lifecycle Management: Closing the Knowledge Loops. Computer-Aided Design \& Applications 2(5), 577-590 (2005)

2. Asiedu, Y., Gu, P.: Product life cycle cost analysis: State of the art review. International Journal of Production Research (1998)

3. Awazu, Y., Baloh, P., Desouza, K.C., Wecht, C.H., Kim, J., Jha, S.: Information communication technologies open up innovation. Research-Technology Management 52(1), 51-58 (2009)

4. Blomberg, J., Giacomi, J., Mosher, A., Swenton-Wall, P.: Ethnographic field methods and their relation to design. In: Schuler, D., Namioka, A. (eds.) Participatory Design: Principles and Practices, pp. 123-156. Lawrence Erlbaum Associates, Mahwah (1993)

5. Brem, A., Voigt, K.I.: Integration of market pull and technology push in the corporate front end and innovation management-insights from the German software industry. Technovation 29(5), 351-367 (2009)

6. Davenport, T.H., Jarvenpaa, S.L., Beers, M.C.: Improving knowledge work processes. Sloan Management Review 37(4), 53-65 (1996)

7. Donati, T., Bricogne, M., Eynard, B.: PLM platform: integrated support of the entreprise digital chain for Collaborative Product Development. In: 7th International Conference on Product Lifecycle Management, Bremen, Germany (2010)

8. Garetti, M., Terzi, S., Bertacci, N., Brianza, M.: Organisational change and knowledge management in PLM implementation. International Journal of Product Lifecycle Management 1(1), 43 (2005)

9. Gunasekaran, A.: Agile manufacturing: a framework for research and development. International Journal of Production Economics 62(1-2), 87-105 (1999)

10. Jun, H.-B., Kiritsis, D.: Several aspects of information flows in PLM. In: Rivest, L., Bouras, A., Louhichi, B. (eds.) PLM 2012. IFIP AICT, vol. 388, pp. 14-24. Springer, Heidelberg (2012) 
11. Khurana, A., Rosenthal, S.R.: Towards holistic "front ends" in new product development. Journal of Product Innovation Management 15(1), 57-74 (1998)

12. Kim, J., Wilemon, D.: Strategic issues in managing innovation's fuzzy front-end. European Journal of Innovation Management 5(1), 27-39 (2002)

13. Li, D., Qiu, M.: State-of-the-art technologies and methodologies for collaborative product development systems. International Journal of Production Research 44(13) (2006)

14. Milicic, A., Perdikakis, A., El Kadiri, S., Kiritsis, D., Ivanov, P.: Towards the Definition of Domain Concepts and Knowledge through the Application of the User Story Mapping Method. In: Rivest, L., Bouras, A., Louhichi, B. (eds.) PLM 2012. IFIP AICT, vol. 388, pp. 58-69. Springer, Heidelberg (2012)

15. Navarro, R., Cloonan, J., Dubois, R., Tiwari, A.: Improving efficiency in Product Lifecycle Management implementation projects by applying lean principles. In: International Conference on Product Lifecyle Management, Eindhoven, Netherlands (2011)

16. Nonaka, I., Takeuchi, H.: The knowledge-creating company: How Japanese companies create the dynamics of innovation. Oxford University Press, USA (1995)

17. Ouertani, M.J., Baina, S., Gzara, L., Morei, G.: Traceability and management of dispersed product knowledge during design and manufacturing. Computer-Aided Design 43(5), 546$562(2011)$

18. Rekiek, B., Dolgui, A., Delchambre, A., Bratcu, A.: State of art of optimization methods for assembly line design. Annual Reviews in Control 26(2), 163-174 (2002)

19. Saaksvuori, A., Immonen, A.: Product Management Lifecycle. Springer (2008)

20. Segonds, F.: Contribution to the integration of a collaborative design environment in the early stages of design, $\mathrm{PhD}$ thesis, Arts et Metiers ParisTech (2011)

21. Sharifi, S., Pawar, K.S.: Product Development Strategies for Agility. In: Agile Manufacturing: The 21st Century Competitive Strategy, pp. 175-197 (2001)

22. Sohlenius, G.: Concurrent Engineering. Annals of CIRP 41, 645-655 (1992)

23. Sriram, R.D.: Artificial intelligence in engineering: Personal reflections. Advanced Engineering Informatics 20(1), 3-5 (2006)

24. Sveiby, K.E.: The new organizational wealth: Managing \& measuring knowledge-based assets. Berrett-Koehler Pub. (1997)

25. Tayaran, E., Schiffauerova, A.: The Role of Internal and External Sources of Knowledge in the Product Lifecycle in Biotechnology Sector. In: Rivest, L., Bouras, A., Louhichi, B. (eds.) PLM 2012. IFIP AICT, vol. 388, pp. 46-57. Springer, Heidelberg (2012)

26. Utterback, J., Suarez, F.: Innovation, competition, and industry structure. Research Policy 22(1), 1-21 (1993)

27. Van der Velden, C., Bil, C., Yu, X., Smith, A.: An intelligent system for automatic layout routing in aerospace design. Innovations in Systems and Software Engineering 3(2), 117128 (2007)

28. Wiig, K.M.: Knowledge management: where did it come from and where will it go? Expert Systems with Applications 13(1), 1-14 (1997) 